\title{
Near-surface sand-dust horizontal flux in Tazhong-the hinterland of the Taklimakan Desert
}

\author{
XingHua YANG ${ }^{1,2}$, Qing HE ${ }^{1,2 *}$, Mamtimin $A L^{1,2}$, Wen HUO ${ }^{1,2}$, XinChun LIU ${ }^{1,2}$ \\ ${ }^{1}$ Institute of Desert Meteorology, China Meteorological Administration, Urumqi 830002, China; \\ ${ }^{2}$ Desert Atmosphere and Environment Observation Experiment of Taklimakan Station, Tazhong 841000, China
}

\begin{abstract}
Tazhong is the hinterland and a sandstorm high-frequency area of the Taklimakan Desert. However, little is known about the detailed time-series of aeolian sand transport in this area. An experiment to study the sand-dust horizontal flux of near-surface was carried out in Tazhong from January to December 2009. By measuring the sand-dust horizontal flux throughout sixteen sand-dust weather processes with a $200-\mathrm{cm}$ tall Big Spring Number Eight (BSNE) sampler tower, we quantitatively analyzed the vertical variation of the sand-dust horizontal flux. And the total sand-dust horizontal flux of different time-series that passed through a section of $100 \mathrm{~cm}$ in width and $200 \mathrm{~cm}$ in height was estimated combining the data of saltation movement continuously recorded by piezoelectric saltation sensors (Sensit). The results indicated that, in the surface layer ranging from $0-200 \mathrm{~cm}$, the intensity of sand-dust horizontal flux decreased with the increase of the height, and the physical quantities obeyed power function well. The total sand-dust horizontal flux of the sixteen sand-dust weather processes that passed through a section of $100 \mathrm{~cm}$ in width and $200 \mathrm{~cm}$ in height was about $2,144.9 \mathrm{~kg}$, the maximum of one sand-dust weather event was about $396.3 \mathrm{~kg}$, and the annual total sand-dust horizontal flux was about $3,903.2 \mathrm{~kg}$. The high levels of aeolian sand transport occurred during daytime, especially from 13:00 to 16:00 in the afternoon. We try to develop a new method for estimation of the detailed time-series of aeolian sand transport.
\end{abstract}

Keywords: aeolian sand transport; horizontal flux; saltation movement; Sensit; Taklimakan Desert

Citation: XingHua YANG, Qing HE, Mamtimin ALI, Wen HUO, XinChun LIU. 2013. Near-surface sand-dust horizontal flux in Tazhong - the hinterland of the Taklimakan Desert. Journal of Arid Land, 5(2): 199-206.

Aeolian sand transport caused by soil wind erosion is a serious problem in many arid regions in the world, and it is considered to be the significant part of global biogeochemical cycles (McTainsh, 2007; Liu, 2009). Furthermore, the sand transport often brings wind sand disasters for humans (Zhao, 1993). Therefore, widespread attention has been attracted to the significance of aeolian sand transport for geomorphology, climatology, meteorology, ecology and environmental sciences (Stout et al., 2009).

The sand-dust horizontal flux is an important parameter for the study on aeolian sand transport (Dong, 2010), as well as an important foundation. The research on sand-dust horizontal flux can improve our understanding of soil wind erosion, aeolian sand transport and wind sand disasters. Before the 1990s, measurement of sand-dust horizontal flux depended mainly on various sand samplers (Bagnold, 1941; Chepil, 1946; Kawamura, 1951; Zingg, 1953; Stout, 1989). For example, the sand sampler of the Big Spring Number Eight (BSNE) sampler was designed in 1986 (Fryrear, 1986). With field and wind tunnel tests, the sampling efficiency of the BSNE sampler was more than $90 \%$ for sand grain size $>100 \mu \mathrm{m}$ (Shao et al., 1993). Nowadays, BSNE sampler has been widely used in the field observation of soil wind erosion.

Since the 1990s, high-frequency sampling systems

"Corresponding author: Qing HE (E-mail: qinghe@idm.cn) 
such as piezoelectric mass flux sensors (Gillette et al., 1997; Van-Donk et al., 2003; Baas et al., 2004; Udo et al., 2009), high-temporal resolution sediment traps (Butterfield et al., 1991; Jackson et al., 1996; Bauer et al., 1998; Davidson-Arnott et al., 2005), and microphonic flux sensors (Ellis et al., 2009) have been applied on the detection of sediment flux. Therefore, measurement of sediment flux was no longer limited to the use of the sand samplers and the sampling frequency was greatly enhanced.

In this study, an experiment in 2009 was developed to measure the sand-dust horizontal flux and saltation movement with a 2-m BSNE sampler tower and piezoelectric saltation sensors (Sensit) in Tazhong, the hinterland of the Taklimakan Desert. The sand-dust horizontal flux data of sixteen sand-dust weather processes and the data of continuous hourly saltation particles from 1 January 2009 to 31 December 2009 were obtained. Based on the relationship between the total sand-dust horizontal flux and saltation particles of each sand-dust weather event, the study estimated the hourly, daily and monthly total sand-dust horizontal flux. The objective of this study was to develop a new method for the estimation of sand-dust horizontal flux.

\section{Physical setting}

With about $85 \%$ of its landforms made up of shifting sand dunes, the Taklimakan Desert, which is located in the central part of the Tarim Basin in Xinjiang Uygur autonomous region, northwestern China (Fig. 1), is the second largest shifting sand desert in the world (Sun and Liu, 2006). It is known as an important sand-dust source and a high-frequency area of China (Wang et al., 2000; Qian et al., 2002; Zhou et al., 2002). The sandstorms, primarily a product of wind erosion in this region have greatly influenced climatic change in East Asia (Zhao et al., 2006). Sand encroachment associated with sandstorms had also damaged oases within the Tarim Basin.

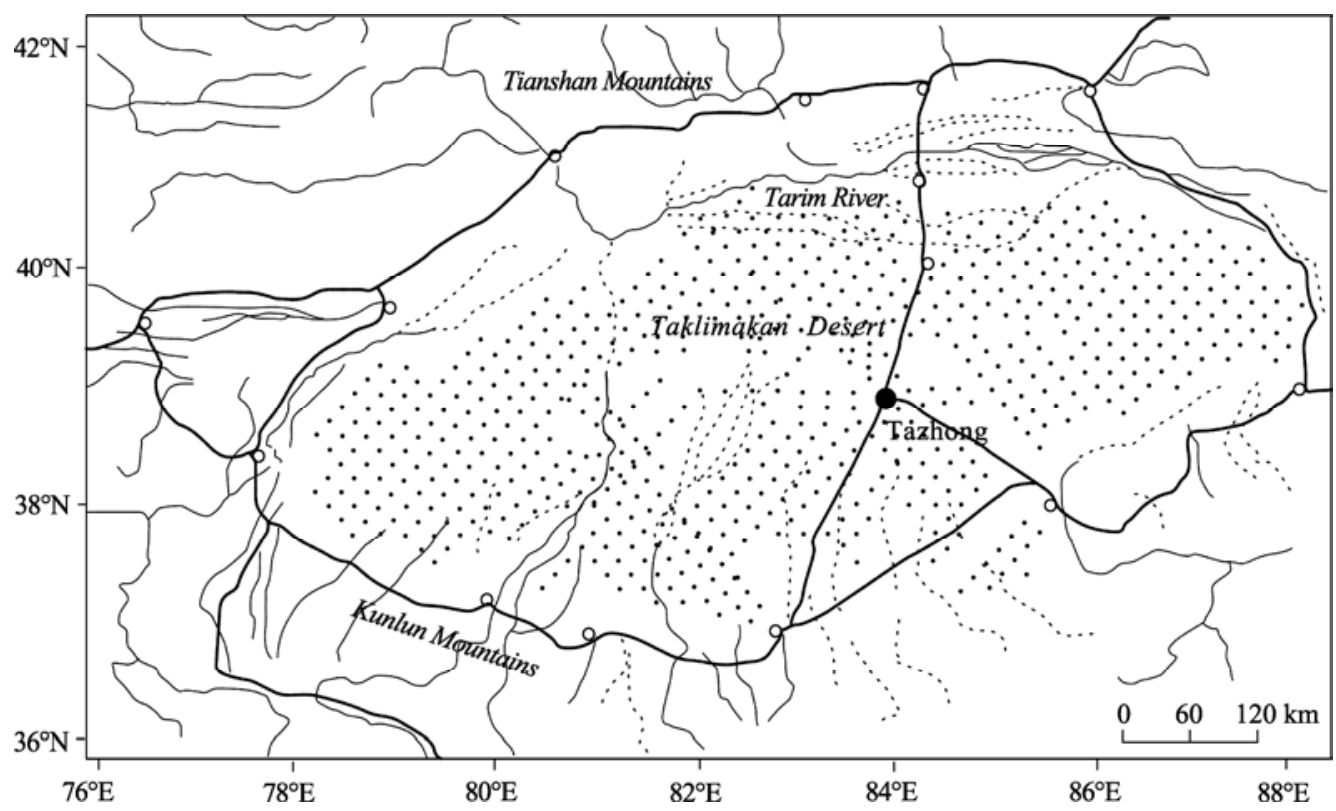

Fig. 1 Location of the Taklimakan Desert within the Tarim Basin. Tazhong is located at the center of the Taklimakan Derert.

Tazhong has a linear distance of $220 \mathrm{~km}$ to the desert edge. The vegetation is rare and the climate is very dry with a precipitation of $25.0 \mathrm{~mm}$ per year. The average annual number of days for sandstorms and blowing sand in any given year is about 100 days (Wang et al., 2003).

The observation site chosen for this study is a flat sandy area, consisting of shifting sand surface. Laboratory test results show that the Sensit could not respond to suspended fine dust (less than $50 \mu \mathrm{m}$ ) (Sensit Company, 2007), so twenty-one samples of surface sand (including dune sand, flat sandy land sand) were obtained from the site and its surrounding area, and measured to obtain the grain size distribution. The 
results showed that these sand samples mainly consisted of fine sand and very fine sand with an average grain size of $147 \mu \mathrm{m}$. About $0.3 \%$ of the grains were smaller than $50 \mu \mathrm{m}$ in size and only $7.6 \%$ had grain sizes greater than $250 \mu \mathrm{m}$.

\section{Monitoring methods}

Sand-dust horizontal flux, saltation activity and wind speed were measured by a sampling system which consisted of a BSNE sand sampler tower, a 200-cm meteorological tower, two piezoelectric saltation sensors and a data collector (CR1000, Campbell).

The sand-dust horizontal flux was sampled by a 200-cm tall BSNE sampler tower, which included an array of six BSNE samplers each attached to a pivoting wind vane and the mounted heights are 5, 10, 20, 50,100 and $200 \mathrm{~cm}$. The BSNE sampler consisted of sampler, metal pan, steel banding and wind vane (Fig. 2 ), and it was fixed to the stent with bearing. Wind vane and bearing could guarantee the sampler turn with the prevailing wind direction and keep the openings oriented parallel to the wind. After each sand-dust weather event, the BSNE samplers were emptied into plastic bags and the actual heights of the sampler openings were measured, then the samples were weighed and the weights were converted to sand-dust horizontal flux per square meter.

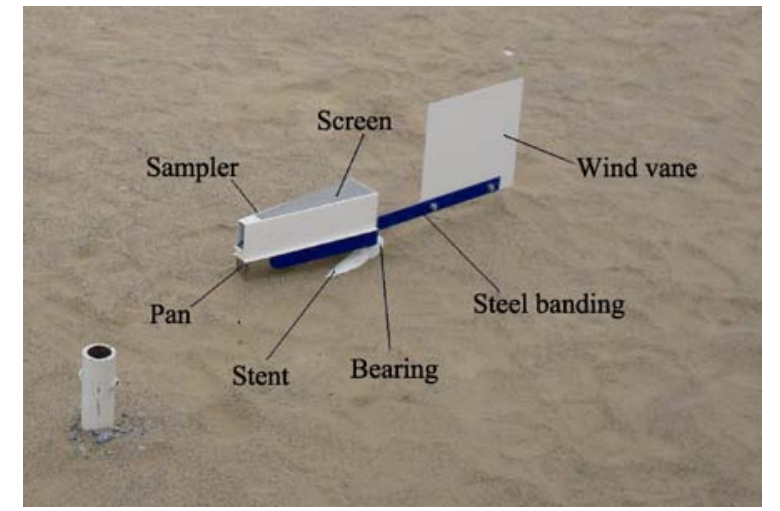

Fig. 2 BSNE sampler measuring different heights of sand-dust horizontal flux

Occurrence of saltation activity was measured by piezoelectric saltation sensor (Sensit) (Fig. 3), which had a $360^{\circ}$ active surface and, thus, had no need to rotate like a BSNE sampler. The center of the active surface of the Sensit was located $5 \mathrm{~cm}$ and $10 \mathrm{~cm}$ above the surface. As saltating particles stroke the active surface, an electrical pulse was generated; these pulses were counted and recorded using a data collector. In this paper, the saltation data at the height of $5 \mathrm{~cm}$ were used to analyze the sand saltation characteristics, the data being sampled at a frequency of $1 \mathrm{~Hz}$.

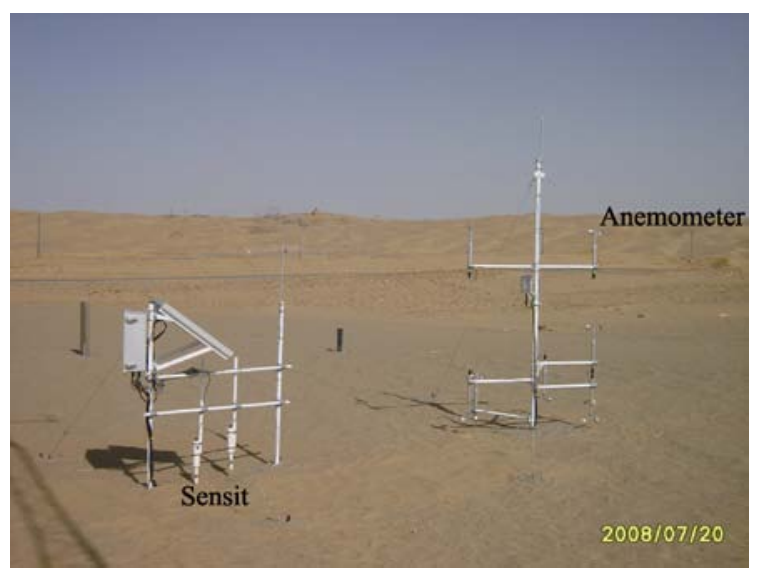

Fig. 3 The meteorological tower (to measure wind speed at heights of $5,10,20,50,100$ and $200 \mathrm{~cm}$ ) and piezoelectric saltation sensor (Sensit)

Wind speed was measured by a $200-\mathrm{cm}$ meteorological tower, with measuring heights being 5, 10, 20, 50, 100 and $200 \mathrm{~cm}$ (WAA151; Vaisala), respectively, and the data being sampled at a frequency of $1 \mathrm{~Hz}$ as well.

\section{Results and discussion}

\subsection{Variation in sand-dust horizontal flux with height}

From 1 January to 31 December 2009 in Tazhong, we observed sixteen sand-dust weather processes except the one occurring between 10 to 12 March. Because of the fault of the BSNE samplers, the sand-dust horizontal flux in the sand-dust weather occurring between 10 to 12 March was not sampled. The duration of each sand-dust weather process is shown in Table 1. For each sand-dust weather process, the sand-dust horizontal flux as a function of height could be expressed using the power function:

$$
q(z)=a(z)^{b} .
$$

Where $q(z)$ is the horizontal flux $\left(\mathrm{kg} / \mathrm{m}^{2}\right), z$ is the 
Table 1 Fitting parameters of the regression analysis for variation in sand-dust horizontal flux as a function of height, and the total amount of sand-dust horizontal flux, and saltation particles of each sand-dust weather event in Tazhong in 2009

\begin{tabular}{cccccc}
\hline $\begin{array}{c}\text { Observations } \\
(\mathrm{dd} / \mathrm{mm} / \mathrm{yy})\end{array}$ & Parameter $(a)$ & Parameter $(b)$ & Fitting $R^{2}$ & Total horizontal flux $(\mathrm{kg})$ & $\begin{array}{c}\text { Saltation particles } \\
\text { (counts) }\end{array}$ \\
\hline $10 / 03 / 09-12 / 03 / 09$ & $2,679.2$ & -0.73634 & 0.9968 & 309.2 & $8,931,114$ \\
$10 / 04 / 09-17 / 04 / 09$ & $3,142.0$ & -1.05150 & 0.9967 & 145.7 & $5,439,487$ \\
$17 / 05 / 09-21 / 05 / 09$ & $2,447.8$ & -0.78189 & 0.9821 & 244.2 & $2,305,483$ \\
$24 / 05 / 09-05 / 06 / 09$ & $2,621.4$ & -1.26237 & 0.9775 & 75.0 & $3,870,965$ \\
$16 / 06 / 09-18 / 06 / 09$ & $4,209.8$ & -1.60905 & 0.9982 & 66.4 & $1,976,187$ \\
$26 / 06 / 09-28 / 06 / 09$ & $2,326.9$ & -0.62070 & 0.9190 & 396.3 & $1,463,189$ \\
$29 / 06 / 09-02 / 07 / 09$ & $15,721.1$ & -2.52114 & 0.9988 & 103.3 & $7,299,052$ \\
$03 / 07 / 09-09 / 07 / 09$ & $4,612.0$ & -1.03536 & 0.9983 & 222.8 & $1,960,720$ \\
$15 / 07 / 09-17 / 07 / 09$ & $9,691.2$ & -1.79661 & 0.9994 & 119.9 & $5,878,580$ \\
$19 / 07 / 09-28 / 07 / 09$ & $6,818.5$ & -1.44599 & 0.9994 & 138.5 & $1,925,673$ \\
$29 / 07 / 09-31 / 07 / 09$ & $5,008.6$ & -1.60467 & 0.9976 & 79.5 & $2,698,615$ \\
$01 / 08 / 09-06 / 08 / 09$ & $1,876.5$ & -1.36097 & 0.9889 & 44.3 & $1,926,907$ \\
$14 / 08 / 09-15 / 08 / 09$ & $3,079.2$ & -1.17410 & 0.9976 & 106.6 & $1,013,667$ \\
$02 / 09 / 09$ & 775.7 & -1.48942 & 0.9911 & 14.7 & $2,569,023$ \\
$13 / 09 / 09-21 / 09 / 09$ & $2,218.5$ & -1.84308 & 0.9908 & 26.0 & 199,156 \\
$22 / 09 / 09-04 / 10 / 09$ & $7,660.4$ & -2.45948 & 0.9959 & 52.5 & 275,314 \\
Total & - & - & - & $2,144.9$ & 392,449 \\
\hline
\end{tabular}

height of the sampler opening above the ground surface $(\mathrm{cm}), a$ and $b$ are fitting parameters. Figure 4 shows that sand-dust horizontal flux decreased with height for the sand-dust weather event occurring from 10 to 17 April 2009. In all cases, the sand-dust horizontal flux decayed rapidly with increasing height.

The parameters $a$ and $b$ as well as the fitting coefficient $R^{2}$ of the sixteen sand-dust weather events are shown in Table 1. We can find that the physical

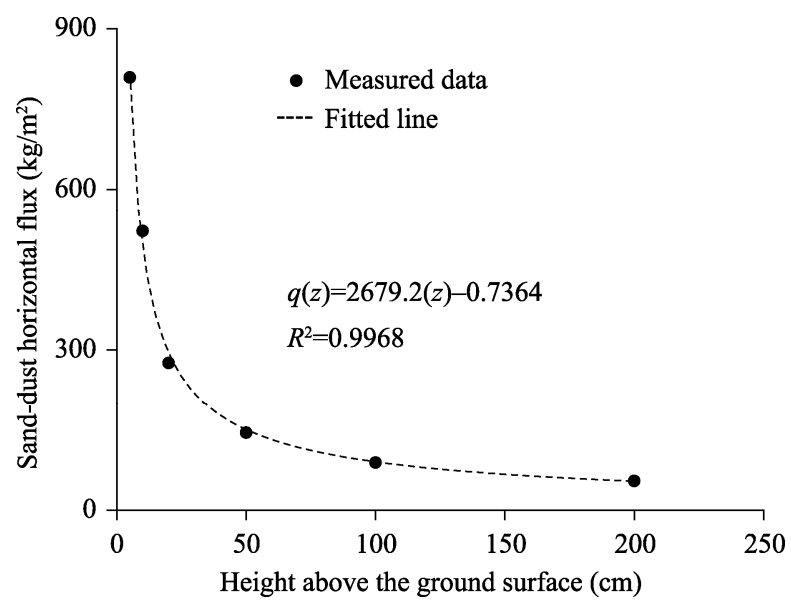

Fig. 4 Sand-dust horizontal flux at different heights above the surface at Tazhong from 10 to 17 April in 2009 quantities of horizontal flux well obeyed power function well of each sand-dust weather process. All fitting coefficients $R^{2}$ were bigger than 0.919 , being different from the result of Chen (1996), whose study showed that the horizontal flux decayed exponentially with height in the north of Taklimakan Desert, and could be expressed using the exponential function:

$$
q(z)=a \exp \left(z^{-b z}\right) .
$$

However, our measured data obey the function not well, and the maximum fitting coefficient $R^{2}$ is only 0.764 , the average value of all fitting coefficient $R^{2}$ is 0.576 . This inconsistent result may be caused by the differences in terrain, sand grain size, measured altitude and sampling efficiency of the sand samplers.

To date, it is widely accepted that the saltation flux decays exponentially with the height (Dong et al., 2006), and suspend flux obeys power function well with the height (Zingg, 1953; Nickling, 1978; Vories and Fryrear, 1991; Fryrear and Saleh, 1993). The average saltation height was calculated according to the result by Wang (2011) and the average particle size, and the saltation height is about $4.8 \mathrm{~cm}$ in Tazhong. Since the lowest observation height in the 
present study was $5 \mathrm{~cm}$, the sand-dust horizontal flux collected by our samplers was predominantly suspend flux. Our result is consistent with previous research.

\subsection{Total sand-dust horizontal flux of different sand-dust weather processes}

According to Eq. 1, the total amount of the sand-dust horizontal flux that passed through a section of 100 $\mathrm{cm}$ in width and $200 \mathrm{~cm}$ in height can be calculated as follows:

$$
Q=\int_{0}^{200} q(z) d z=\frac{a}{b+1}\left[(200)^{b+1}-1\right] .
$$

Where, $Q$ is the total horizontal flux of each sand-dust weather process $(\mathrm{kg})$. By using Eq. 3, we calculated the total amount of the sand-dust horizontal flux of each sand-dust weather event and the results are shown in Table 1. Among the sixteen sand-dust weather events, the maximum total horizontal flux was $396.3 \mathrm{~kg}$ occurring between 29 June and 2 July 2009 , while the minimum was only $14.7 \mathrm{~kg}$ occurring between 13 and 21 September 2009. The mean total horizontal flux was $153.1 \mathrm{~kg}$ and the total amount of the sand-dust horizontal flux of all sixteen sand-dust weather events is $2,144.9 \mathrm{~kg}$. The total amount of the sand-dust horizontal flux in Tazhong during each sand-dust weather event was small compared to what has been measured at other locations. Highly erodible, burned grassland in Meade, Kansas, had total horizontal flux as high as $800 \mathrm{~kg}$ per sandstorm (Donk et al., 2003). As we know, the amount of the sand-dust horizontal flux was closely related with the intensity of sandstorm. Tazhong being affected by its landform and geographical position, experiences less strong sandstorms. It can also be seen from the values of the total amount of the sand-dust horizontal flux of each sand-dust weather event that the total amount of the sand-dust horizontal flux was larger in spring and summer, in comparison with autumn, which indicates that the sediment transport intensity in autumn was weak.

\subsection{Estimation of the total amount of sand-dust horizontal flux of different time-series}

In this study, we can only calculate the total amount of sand-dust horizontal flux of each sand-dust weather event with the data measured by BSNE samplers. To further understand the changes of the aeolian sand transport in Tazhong, more detailed data is needed. The saltation particle data measured by piezoelectric saltation sensors (Sensit) may be useful for this consideration, if the relationship to the total amount of sand-dust horizontal flux is known. Some authors had reported that there was a linear relationship between the total amount of sand-dust horizontal flux and the amounts of saltation particles measured by Sensit (Gillette et al., 1997; Van-Donk et al., 2003). The relationship between the amounts of saltation particles and the total amount of sand-dust horizontal flux of the sixteen sand-dust weather events is shown in Fig. 5. From Fig. 5, we can see that there is a good linear relationship between them, a correlation coefficient $R^{2}$ is 0.9196 with a significance level of 0.001 . The equation is as follows:

$$
Q=0.0512 \text { counts . }
$$

Where, $Q$ is the total horizontal flux of each sand-dust weather process $(\mathrm{kg})$, counts is the sum of saltation particles measuered by Sensit during corresponding sand-dust weather process (thousand counts). Then, according to Eq. 4 and the data of saltation particles, the hourly, daily and monthly total amount of sand-dust horizontal flux were estimated, and the results are shown in Figs. 6-8.



Fig. 5 The amount of sand-dust horizontal flux of each sand-dust weather event, measured by BSNE samplers, and saltation particles, measured by Sensit

In this paper, the hourly total sand-dust horizontal flux was estimated and summed for a given 'time of 
day' for all days. For example, if we choose the hour 12:00 as the 'time of day', then we simply sum all total horizontal flux of this hour for every day. The same process was repeated for all other hours and the results are shown in Fig. 6.

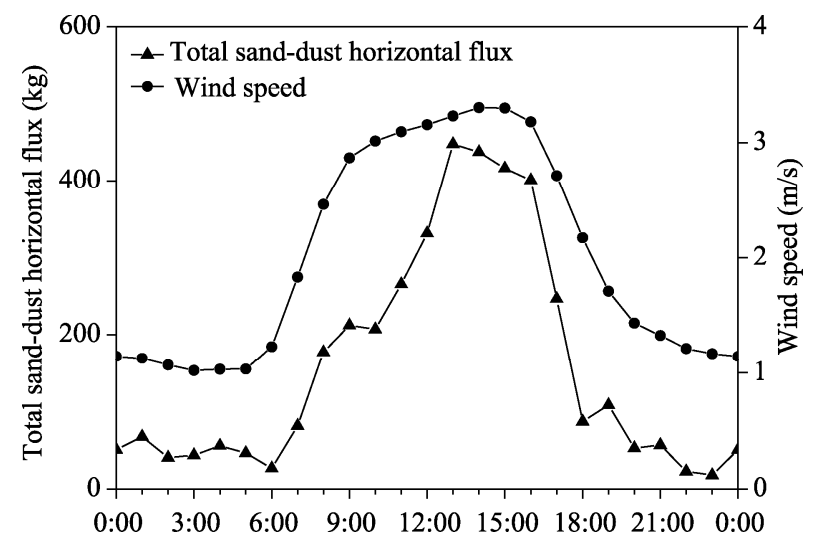

Fig. 6 Diurnal variation of total sand-dust horizontal flux based on Sensit counts and its relationship with the mean wind speed at 2-m height

Aeolian sand transport can occur at any hour of the day in Tazhong. High levels of aeolian sand transport occurred during daytime and relatively low levels occurred at night and early morning. High levels of aeolian sand transport were maintained from 11:00 to 17:00 Local Standard Time (LST), especially from 13:00 to 16:00 LST in the afternoon, which accounted for $43.7 \%$ of the total sand-dust horizontal flux. The maximum appeared at 13:00 LST, which was $448.0 \mathrm{~kg}$. After that, a rapid decrease in aeolian sand transport occurred, and reached the minimum at the night at 23:00 LST, which was only $17.9 \mathrm{~kg}$.

The diurnal variation of total sand-dust horizontal flux was similar to the distribution of wind speed. However, there are some interesting phenomena, for example, the maximum total sand-dust horizontal flux appeared at 13:00 LST, while the maximum wind speed appeared at 14:00 LST. Some hours had larger total sand-dust horizontal flux with lower wind speed. This can be explained by the fact that sometimes strong intermittent gusts can produce intense bursts of aeolian sand transport.

Figure 7 shows the temporal variation of daily total sand-dust horizontal flux. The large amount of aeolian sand transport mainly occurred in spring and summer, which was consistent with the occurrence time of

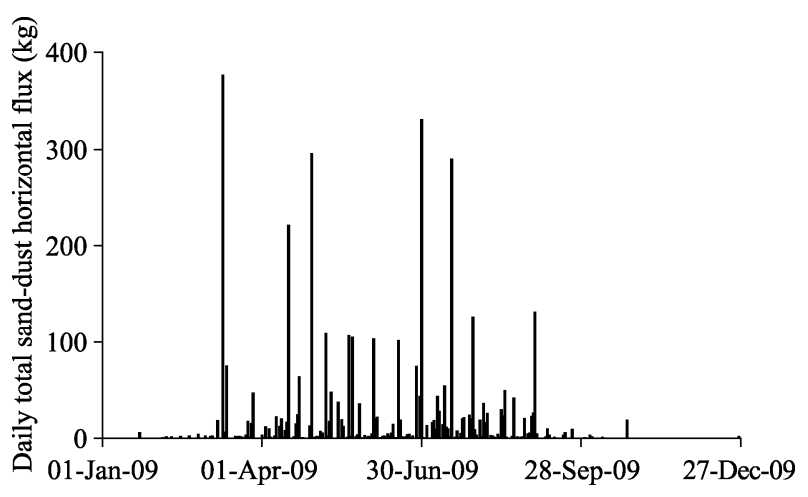

Fig. 7 Daily total sand-dust horizontal flux based on Sensit counts

sand-dust weather events. From Table 1, it can be found that the sixteen sand-dust weather processes mainly occurred in spring and summer, with fewer occurrences in autumn and winter. Among them, three ones occurred in spring, twelve ones in summer, one in autumn and no sand-dust weather event was observed in winter. More than half of the total aeolian sand transport in 2009 occurred in a few days, and the maximum was $376.4 \mathrm{~kg}$, occurring on 10 March 2009.

The monthly total sand-dust horizontal flux between January and December 2009 was compared (Fig. 8). Aeolian sand transport mainly occurred in March, April, May, June, July, August and September, and these months accounted for $98.8 \%$ of the annual total amount, which indicates that sand activities in Tazhong in winter and late autumn were relatively infrequent. In June, the aeolian sand transport reached to the greatest $765.3 \mathrm{~kg}$. Figure 8 also shows that the monthly total sand-dust horizontal flux had a much

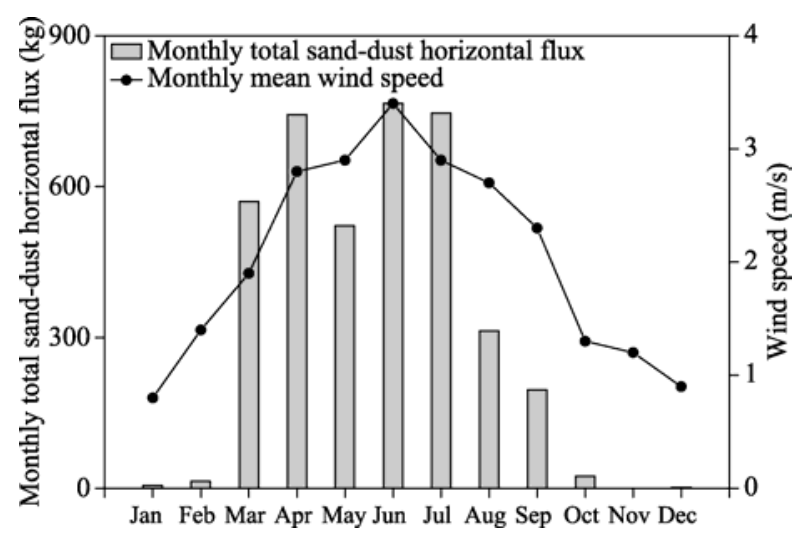

Fig. 8 Monthly total sand-dust horizontal flux based on Sensit counts and its relationship with the monthly mean wind speeds at 2-m height 
better correlation with monthly mean wind speeds, which indicates that the occurrence of aeolian sand transport in Tazhong depends on wind speeds.

The annual total amount of sand-dust horizontal flux estimated using Eq. 4 was about $3,903.2 \mathrm{~kg}$, while the total amount of the sand-dust horizontal flux of all sixteen sand-dust weather events was $2,144.9 \mathrm{~kg}$, accounting for $55.0 \%$ of the annual total horizontal flux. Thus, it can be seen that sand-dust weather events play an important role in the aeolian sand transport. Previous study showed that the annual total amount of sand-dust horizontal flux was about 306.9 $\mathrm{kg}$ for Mojave Desert, USA (Donk et al., 2003), 6,512.5 $\mathrm{kg}$ for Minqin and 6.2 $\mathrm{kg}$ for Tengger Desert (Dong, 2010; Zhang et al., 2011). Minqin, Tazhong and Tengger Desert coexist in Northwest China, the annual total amount of sand-dust horizontal flux was significantly different among the three areas, especially between Minqin and Tengger Desert. Sediment transport is a complicated process, and is affected by regional climate, ground surface conditions and weather process. We can only partially explain the differences in the amount of sand-dust horizontal flux between Minqin, Tazhong and Tengger Desert from the variations in ground surface conditions and wind speeds. The ground surfaces are covered by sandy materials and vegetation is rare in the three observation sites, but the mean grain sizes of dune sediments range from 0.09 to $0.25 \mathrm{~mm}, 0.1$ to $0.2 \mathrm{~mm}$ and 0.22 to $0.26 \mathrm{~mm}$ in Minqin, Tazhong and Tengger deserts, respectively, indicating that the critical threshold is highest in Tengger Desert. The mean wind speeds during the observation period were 2.5, 2.0 and $2.3 \mathrm{~m} / \mathrm{s}$ in Minqin, Tazhong and Tengger Desert, respectively (Dong, 2010; Zhang et al., 2011), indicating that Minqin had the best dynamic conditions for sediment transport. Meteorological records revealed that the frequency of severe sandstorms is higher in Minqin than in any other parts of China (Qian et al., 2002).

\section{Conclusions}

We monitored the sand-dust horizontal flux of sixteen sand-dust weather events with BSNE sampler tower and the saltation activities with piezoelectric saltation sensors (Sensit) in Tazhong in 2009. The results suggest that the variation in sand-dust horizontal flux with height can be better described with the power function of $q(z)=a(z)^{\mathrm{b}}$.

In this study, we have estimated the hourly, daily and monthly total sand-dust horizontal flux based on the saltation particles data. This method may offer automatically sand-dust horizontal flux of different time-series in future, and more data of the sand-dust horizontal flux and saltation particles are necessary so as to establish more exact relation between them.

The total amount of sand-dust horizontal flux of all sixteen sand-dust weather processes in 2009 through a section $100 \mathrm{~cm}$ in width and $200 \mathrm{~cm}$ in height was $2,144.9 \mathrm{~kg}$, the annual total sand-dust horizontal flux in 2009 was about 3,903.2 kg. In Tazhong, high levels of aeolian sand transport occurred during daytime, especially from 13:00 to 16:00 in the afternoon. The aeolian sand transport of March to September accounts for $98.8 \%$ of the annual total amount, the monthly total sand-dust horizontal flux had a much better correlation with monthly mean wind speed.

\section{Acknowledgments}

This research was funded by the National Natural Science Foundation of China (41175017), the Central Scientific Research Institute of the public basic scientific research business professional ( IDM201103), and the R\&D Special Fund for Public Welfare Industry (Meteorology) (GYHY201106025).

\section{References}

Baas A C W. 2004. Evaluation of saltation flux impact responders (Safires) for measuring instantaneous aeolian sand transport intensity. Geomorphology, 59: 99-118.

Bagnold R A. 1941. The Physics of Blown Sand and Desert Dunes. New York: Methuen.

Bauer B O, Namikas S L. 1998. Design and field test of a continuously weighing, tipping-bucket assembly for aeolian sand traps. Earth Surface Processes Landforms, 23: 1173-1183.

Butterfield G R. 1991. Grain transport rates in steady and unsteady turbulent airflows. Acta Mechanica, 1: 97-122.

Chen W, Yang Z, Zhang J, et al. 1996. Vertical distribution of wind-blown sand flux in the surface layer, Taklamakan Desert, Central Asia. Physical Geography, 17: 193-218.

Chepil W S. 1946. Dynamics of wind erosion: V. Cumulative intensity of soil drifting across eroding fields. Soil Science, 61: 257-263. 
Davidson-arnott R G D, Mac-Quarrie K, Aagaard T. 2005. The effect of wind gusts, moisture content and fetch length on sand transport on a beach. Geomorphology, 68: 115-129.

Dong Z B, Man D Q, Luo W Y, et al. 2010. Horizontal aeolian sediment flux in the Minqin area, a major source of Chinese dust storms. Geomorphology, 116: 58-66.

Dong Z B, Qian G Q., Luo W Y, et al. 2006. Analysis of the mass flux profiles of an aeolian saltating cloud. Journal of Geophysical Research-Atmospheres, 111, D16111. doi: 10.1029/2005 JD006630.

Ellis J T, Morrison R F, Priest B H. 2009. Detecting impacts of sand grains with a microphone system in field conditions. Geomorphology, 105: 87-94.

Fryrear D W. 1986. A field dust sampler. Journal of Soil and Water Conservation, 41: 117-120.

Fryrear D W. 1991. Soil losses by wind erosion. Soil Science Society of America Journal, 59: 668-672.

Fryrear D W, Saleh A. 1993. Field wind erosion: vertical distribution. Soil Science, 155: 294-300.

Gillette D A, Fryrear D W, Xiao J B, et al. 1997. Large-scale variability of wind erosion mass flux rates at Owens Lake: I. Vertical profiles of horizontal mass fluxes of wind-eroded particles with diameter greater than $50 \mu \mathrm{m}$. Journal of Geophysical Research: Atmospheres, 102: 25977-25987.

Jackson D W T. 1996. A new instantaneous aeolian sand trap design for field use. Sedimentology, 43: 791-796.

Kawamura R. 1951. Study on sand movement by wind. Report of Institution of Science and Technology. Tokyo: University of Tokyo.

Liu T S. 2009. Loess and Arid Environment. Hefei: Anhui Science and Technology Press.

McTainsh G, Strong C. 2007. The role of aeolian dust in ecosystems. Geomorphology, 89: 39-54.

Nickling W G. 1978. Eolian sediment transport during dust storms: Slims River Valley, Yukon Territory. Canadian Journal of Earth Sciences, 15: 1069-1084.

Qian Z A, Song M H, Li W Y. 2002. Analyses on distributive variation and forecast of sand-dust storms in recent 50 years in North China. Journal of Desert Research, 2: 106-111.

Sensit Company. 2007. Technical Description for the New Model H11-LIN. Portland: Sensit Company, 13-14.
Shao Y, McTainsh G H, Leys J F. 1993. Efficiency of sediment samplers for wind erosion measurement. Australian Journal of Soil Research, 31(4): 519-531.

Stout J E. 1989. Performance of a windblown-particle sampler. Transactions of the ASAE, 32(6): 2041-2045.

Stout J E, Warren A, Gill T E. 2009. Publication trends in aeolian research: an analysis of the bibliography of aeolian research. Geomorphology, 105: 6-17.

Sun J M, Liu T S. 2006. The age of the Taklimakan Desert. Science, 312: 1621.

Udo K. 2009. New method for estimation of aeolian sand transport rate using ceramic sand flux sensor (UD-101). Sensors, 9: 9058-9072.

Van-donk S J, Huang X, Skidmoren E L, et al. 2003. Wind erosion from military training lands in the Mojave Desert, California, USA. Journal of Arid Environments, 54: 687-703.

Vories E D, Fryrear D W. 1991. Vertical distribution of wind-eroded soil over a smooth, bare field. Transactions of the ASAE, 34(4): 1763-1768.

Wang S G, Dong G R, Chen H Z, et al. 2000. Advances in studying sand-dust storms of China. Journal of Desert Research, 4: 349-356.

Wang X, Ma Y, Chen H W, et al. 2003. Analysis on the climatic characteristics of sandstorms in south Xinjiang. Journal of Desert Research, 2: 147-151.

Wang T. 2011. Sand control project in China. Beijing: Science Press, 86-93.

Zhang Z C, Dong Z B, Zhao A G. 2011. The characteristics of aeolian sediment flux profiles in the south-eastern Tengger Desert. Sedimentology, 58: 1884-1894.

Zhao T L, Gong S L, Zang X Y, et al. 2006. A simulated climatology of Asian dust aerosol and its transpacific transport. Part I: Mean climate and validation. Journal of Climate, 19: 88-103.

Zhao X. 1993. Damages and countermeasures of catastrophic sandstorm occurred in Gansu province. Journal of Desert Research, 13: 1-7.

Zhou Z J, Wang X W, Niu R Y. 2002. Climate characteristics of sandstorm in China in recent 47 years. Journal of Applied Meteorological Science, 2: 193-200.

Zingg A W. 1953. Wind tunnel studies of the movement of sedimentary material. $5^{\text {th }}$ Hydraulic Conference Proceedings. Iowa: Iowa Institute of Hydraulic. 